\title{
Evaluation of Disparities between Transportation Needs and Trip Patterns of Men and Women in Kandahar City, Afghanistan
}

\author{
Mohibullah Rahmat ${ }^{1,2}$, Shoshi Mizokami² \\ ${ }^{1}$ Department of Civil Engineering, Faculty of Engineering, Kandahar University, Kandahar, Afghanistan \\ ${ }^{2}$ Graduate School of Science and Technology, Kumamoto University, Kumamoto, Japan \\ Email: ^mohib.rahmat@gmail.com, smizo@gpo.kumamoto-u.ac.jp
}

How to cite this paper: Rahmat, M. and Mizokami, S. (2019) Evaluation of Disparities between Transportation Needs and Trip Patterns of Men and Women in Kandahar City, Afghanistan. Journal of Transportation Technologies, 9, 78-94. https://doi.org/10.4236/jtts.2019.91005

Received: October 3, 2018

Accepted: January 1, 2019

Published: January 4, 2019

Copyright (c) 2019 by authors and Scientific Research Publishing Inc. This work is licensed under the Creative Commons Attribution International License (CC BY 4.0).

http://creativecommons.org/licenses/by/4.0/

(c) (i) Open Access

\begin{abstract}
Consideration of gender equality in transportation planning is quite a new phenomenon. However, its significance is discussed widely by several researchers, particularly, in developing countries. In Kandahar city of Afghanistan, women have limited choices when it comes to using transportation services. With respect to some cultural, social, contextual, environmental, technological and physical barriers; women do not receive equal services from the current transport sectors. Using Revealed Preference and Stated Preference techniques, a survey was conducted in Kandahar city to identify the differences between trip patterns and transportation needs among men and women of the city. Our findings show distinct and clear disparities in socio-demographic characteristics of men and women of Kandahar city leading to trip disparities. Almost all of women do not own any types of personal vehicles, they are less educated and do not have jobs. Likewise, there is a considerable gap between trip characteristics and patterns of men and women. Majority of female trips are for educational purposes while male trips are more dispersed over multiple activities. Motorcycle is the most dominant and preferred mode for men, while women are mostly walking or using available public transit. Compared to men, women were recorded to have lesser trips per day over short distances. Transportation choices of women are also limited to walking, accompanying other male members of family or using public modes. However, men are generally using their private cars, motorcycles and bicycles together with all those options available for women. The results of Multinomial Logit Model showed that all selected variables such as vehicle ownership, income, travel cost and time will be significant factors for mode
\end{abstract}


choice behavior of men, though for female respondents travel time and travel cost are main factors.

\section{Keywords}

Trip Patterns, Gender, Transportation, Needs, Kandahar, Afghanistan

\section{Introduction}

In most countries, gender equality is considered to be a part of the political dialogues. However, this relatively new and essential issue is now discussed in almost all scientific and social studies. Recent studies show that consideration of various transportation needs of men and women in the process of planning transportation systems which is a relatively new issue even in the United States and Western Europe is an extensively important and vital subject.

Various researchers and scholars have studied the cross-cultural features of gender mobility and travel behaviors of women. Furthermore, these studies examined various aspects of women and mobility in terms of the travel patterns and times, the correlation of gender policies and transport, the connection between policies and ongoing projects and possibilities of including ICT in transport and gender related projects [1].

The travel patterns of men differ significantly from those of women. These disparities are generally linked to gender inequality, education, socialization, culture and urban structures [2]. However, numerous studies show similarities between the travel patterns of female travelers amongst industrialized and developing countries. Be it large city or a small one, rural or urban areas, the complexity of women activities are much higher than those of men. Women are mostly involved in the household activities such as taking care of children, the elderly and the ill. As a result, it generates more trips during off-peak hours with variety of destinations compared to the trips made by men [3].

The differences in travel patterns between men and women are generally attributed to their split roles in families and labor markets. However, the participation of women in labor market has increased significantly in recent years; still the types and forms of employment remain different. Women often like to work closer to homes and are likely to have care taking professions with lower salaries and working conditions as well as limited executive and managerial positions [3].

The number of daily trips taken by women is comparatively higher than those of men, however, women tend to travel shorter distances [4] [5]. The reasons behind these findings are believed to be the tendency of women to work closer to their houses as well as their lower wages and income levels. It is believed that in order to save money, poor women will most likely choose walking rather than using public transportation which makes them more vulnerable to the long distances [4]. The type of job i.e. part-time or full-time jobs are also believed to 
have a strong impact on the distance of trips. This fact is reinforced by a research conducted in Germany which shows that people who are working part-time jobs take more trips per day over short distances compared to full-timers [6]. Another differentiating characteristic of women trips are the zigzagged or crisscrossed behavior of their trips. Meaning women generally tend to take multiple trips rather than just going from one place to another. This movement is explained by the scholars as trip-chaining. Normally, this chaining results in getting off at several destinations, generation of trips during off peak hours and payment of multiple fares while using public transport [7]. Other travel surveys from Asian countries also confirm the European findings. A survey from Ashgabat city of Turkmenistan found that male and female routines while using public transit differed significantly as $29 \%$ of women were recorded to be walking to work compared to the $14 \%$ of men [8].

One of the most effective ways for reduction of urban inequality in terms of providing sustainable transport is provision of regular public transportation system. Multiple researches from the globe suggest that women are dependent more on public transport compared to men even in the developed countries. A study from France show that almost two-third of public transport users are women [3]. Similarly, a study conducted in the United States carried in 2007 [2], found that $55 \%$ of public transport users were female. A German study also found that female ridership of public transit is higher than male [9].

\section{1) The Barriers}

Consideration of gender in designing, planning and implementing effective transportation systems may come up with multiple cultural, social, contextual, environmental, technological and physical barriers. Furthermore, lack of sufficient statistical data has also been considered as one of the main barriers to transportation planners who are willing to consider the needs of women and other social groups in the process of planning transportation systems. The availability of the statistical data is very vital for understanding the disparities between the characteristics of men and women travelers such as frequency, distance, purpose of the trips, mobility, accessibility and other relevant features [3] [10]. Some of the most common barriers encountered by transportation planners are discussed as follows:

\section{Personal Security/Safety}

It is a globally accepted fact that women experience fear, violence and sexual harassment both verbal and physical, while accessing and using public transit. Dark and distanced stops, congested and crowded vehicles, limited access to transit related information, lack of space, unreliable services and absence of other safety measures are believed to have a higher impact on women compared to men [11]. There is evidence from all over the world particularly the developing countries to prove this claim. Multiple studies from India show that Indian women face various types of harassments even during day time [12]. This study further states that $51.4 \%$ of surveyed women by Jagori organization reported to have faced harassment while using public transit. Likewise, $49 \%$ of surveyed men 
reported to have witnessed women being harassed. A similar study conducted in Delhi in 2010 demonstrated that women faced higher level of sexual harassment on roadsides as well as during their trips using public transit. The studies by UN Women [11], showed that two third of women faced sexual harassments between 2 - 5 times in the previous year. Another study in the city of Chennai showed that $66 \%$ of the surveyed women reported to have been sexually harassed while commuting [13].

Fear, nervousness, anxiety and concerns about safety and security are believed to be vital detractors from use of public transport [14]. Public may avoid certain routes or stops; do not use them at nights or at all if they felt that they may witness harassment.

Public transportation is a convenient and sustainable mode of transportation for both men and women. However, some fear and safety concerns will result in shift from public transit to private modes particularly by female users. Numerous studies in the past have shown the influence of fear and safety concerns on travel decisions. UK Department for Transport [15], conducted a survey which showed that $10.5 \%$ of extra trips would have been generated if the public sensed enough safety and security while traveling. This study further states that the results of a survey conducted in the Los Angeles city shows that bulk of the car owners would use public transport if they believed it is safe and clean [15]. Likewise, another research identified that women felt unsafe when the services are not comfortable, while waiting for long times at bus stations, when the safety measures are not properly indicated and when there is lack of information about bus services [12].

In some studies women are reported to feel less fear while the vehicles are not empty and they witness the presence of additional staff. A survey conducted by Department of Transport in the UK in 2002 [15], shows that while traveling by bus, women favor additional staff members and prefer the refusal of the drivers to allow the drunken and drug-affected passengers, however, male passengers were reported to prefer the availability of CCTV (closed-circuit-television) or in-vehicle radios. The increasing trend of using CCTV cameras by many transportation agencies at bus stops and stations seems to deliver some level of comfort and release to women travelers [15].

\section{Physical Barriers}

These barriers are normally associated to the design and types of stations, platforms and vehicles of public transportation. Lack of convenient stairs, escalators, elevators and proper floorings may cause several problems to the passengers traveling with packages and/or children and children's strollers. Similarly, absence of sufficient storage space in stations as well as buses and trains makes it very difficult for these travelers to bring their strollers or luggage inside the vehicle which results in avoiding the use of public modes for daily trips [16]. Though it is very difficult to specify the direct effect of "bad design" of public spaces and stops on the safety, still there is evidence proving the positive impacts of good designs [17]. 
The specific design attributes of transportation settings are also found to induce nervousness and fear among the transit users. People normally fear if the surroundings are dark; the stops have many corners and nooks where someone can hide and when they do not see any possibilities of escape in emergencies. Dark underground stations, underpasses and tunnels are termed more feared compared to ground-leveled and open transit facilities [18].

\section{Affordability Barriers}

Allocation of affordable fares for all modes of public transit is a very important issue in planning and operating public transport systems. Particularly, female population should be considered during the process of fare allocations as they are found to make frequent trips. In most of the developing countries, women are financially not independent and their transport expenses are provided by male members of the family such as father, husband and son. Therefore, higher transit fares will make them avoid using the public transportation. A transportation survey conducted by the World Bank [19], in seven developing countries between 2008 and 2010 shows that one of the main factors not allowing women to use transportation is the high cost of the transport. In order to solve this problem or at least decrease it, for governments and transportation agencies, it is a common agenda to consider discount strategies to women and the elderly. For instance London provides a 50\% discount for the low income people and part-time jobbers, while any passenger with an age of over 60 years will get a free transportation [20]. In similar case, Swedish authorities also offer several discount schemes for using public transportation and particularly women are enjoying these offers more than men do [21].

\section{2) The Context of Kandahar}

Kandahar city is the center of a large cultural and political region "Loy Kandahar". Kandahar city, the third largest city in the country and the previous capital of Afghanistan is located $457 \mathrm{~km}$ southeast of the current capital Kabul. Due to its strategic location along the routes between Central Asia, Iran and Indian subcontinent, Kandahar has always been the center of domestic and regional wars and conflict which has tremendously affected the development of the region. According to the statistical data, the population of Kandahar city was recorded at 385,700 persons in 2011 and 448,262 persons in 2016 which indicates a distinct growth. Almost half $(217,518)$ of that amount is registered as female [22]. This is not only for Kandahar city, on the country level in terms of gender; Afghanistan has one of the most balanced populations in the world with a female portion of $49 \%$ [22]. However, there are multiple studies and reports showing lack of gender considerations in most of the development policies, plans and operations.

As discussed earlier, the transportation needs and travel patterns of men and women are considerably different, particularly in developing countries. In case of Afghanistan, there is limited data on relationship between gender and transportation such as how women and men use transportation; how access to transportation is linked to the labor market and how gender and transport is related 
to health and education. Likewise, the data about traditional transportation such as traffic counts and trip dairies are lacking. All these factors put an extra pressure in formulating the gender issues in planning, operating and maintaining transport systems [19]. Some cultural, contextual and religious rules and regulations do not permit women of Kandahar to drive/ride a car, motorcycle or bicycle. However, there are no governmental laws to prevent women from doing so; still women do not feel safe to drive or at least it is not perceived well by the majority of public. These obstacles leave only few options for women of Kandahar to travel from one place to another. They can use the available public modes; take a ride with their family members or just walk. If we go a little in details; every one of the mentioned alternatives have numerous problems of their own. Walking is a very effective and environmentally friendly option, though; it is not always a feasible one specifically for longer trips and for the elderly and children. Using the services of other male family members also possess multiple barriers for easy movement. Women will have to organize their trips i.e. timing and destinations with reference to the trips of other family members. Researchers have found that women in developing countries normally travel during off peak hours; however, if women in Kandahar are to travel with their family members, they will have to travel in the morning while men leave for work. The third option of using public transit also comes up with number of barriers which are briefly discussed below.

Kandahar city does not have a regular public transportation system and the only available public modes are provided by paratransit system. There are multiple deficiencies associated to the services of the paratransit; particularly their offers to women are very limited. The major problem with this sector is their limited accessibility as these vehicles do not operate on minor or local roads, which makes it very difficult for women to access a public transit vehicle within the residential areas. The availability of seats is another key problem for women. With respect to the Islamic Religion, women cannot set beside a stranger male passenger under any circumstances; therefore, they will have to hire a private taxi which will cost a lot of money. With reference to the cost of the public modes in Kandahar city, paratransit can be divided into two groups. The first group includes taxis which are operating on fixed routes and the vehicle is shared by multiple passengers which decreases the amount of fare. However, these vehicles are not available everywhere. The second group is normal taxis, available for hire at almost all parts of the city and will go everywhere, but the fares for these taxis are much higher than the first group and low to middle income families are not able to afford these services.

\section{Materials and Methods}

Some of diversely populated districts of Kandahar City were selected for collection of data for this study. We tried to include poor, middle class and high class residents of Kandahar city in the survey which was conducted in September and October of 2016. In order to consider transport needs of various residents, the 
survey areas included districts with migrants from other parts of the country and newly developed districts with high class living conditions.

Stated Preference (SP) and Revealed Preference (RP) techniques were used to design the questionnaire for collection of the data. The questionnaire was developed with three distinct sections. The first section was aimed to collect socio-demographic and household data. This part asked the head of the families to record their family incomes, vehicle ownership and the demographics of their family members such as age, occupation, sex, possession of license, level of education and marital status. They were further asked to rate their satisfaction levels from public transit and private modes on a five point scale of satisfaction ranging from very dissatisfied to satisfied. The second section of the questionnaire was developed to collect the data about trip dairies for one working day. This segment was prepared to register trip information for all trips taken in one day. The information included the start and end time of the trip, mode used for the travel, purpose of the trip, accompanying people and total distance travelled. The final section was designed for Stated Preference survey. SP choices were designed with reference to (Fractional Factorial Design). Four transportation modes were selected to organize the SP choice sets. These included three currently available modes i.e. taxi, private car and motor cycle and one mode as a future plan (Bus). These four modes were further divided into two groups of public and private modes. Taxi and bus had three attributes of travel time, travel cost and waiting time while the private modes of car and motorcycle had two attributes of travel cost and travel time. All attributes had three levels. With respect to the high number of runs for this particular design, it was decided to divide the choices into 9 groups resulting in three sets for every individual (Table 1). The questionnaires were spread at schools, universities, restaurants and other offices. A sum of 1500 questionnaires was distributed to 300 households. We received a total of 1000 questionnaires back and only 603 questionnaires coming from 180 households were eligible for use in this study.

\section{1) Method of Analysis}

In order to analyze the SP choices we decided to use the mathematical approach of discrete choice modelling which has a fair applicability for predicting

Table 1. Sample of SP choices.

\begin{tabular}{|c|c|c|}
\hline Options & Modes & Trip Attributes \\
\hline A & Private Car & $\begin{array}{l}\text { Travel Cost }=40 \mathrm{AFN} \\
\text { Travel Time }=35 \mathrm{~min} .\end{array}$ \\
\hline B & Private Motorcycle & $\begin{array}{l}\text { Travel Cost }=30 \mathrm{AFN} \\
\text { Travel Time }=25 \mathrm{~min} .\end{array}$ \\
\hline $\mathrm{C}$ & Regular Bus & $\begin{array}{l}\text { Travel Cost }=15 \mathrm{AFN} \\
\text { Travel Time }=45 \mathrm{~min} . \\
\text { Waiting Time }=20 \mathrm{~min} .\end{array}$ \\
\hline $\mathrm{D}$ & Taxi & $\begin{array}{l}\text { Travel Cost }=150 \mathrm{AFN} \\
\text { Travel Time }=45 \mathrm{~min} . \\
\text { Waiting Time }=5 \mathrm{~min} .\end{array}$ \\
\hline
\end{tabular}

Assume a fixed trip from home to office! 
individual choices with respect to the attractiveness and utility of the modes. To be more precise, Multinomial Logit Model (MNL) was used and utility functions were developed for all modes to analyze the SP choices. We did not modify any parts of the MNL model and used the typical form of the model with the following utility function:

$$
\begin{gathered}
V_{j}=\beta_{1} * X_{j 1}+\beta_{2} * X_{j 2}+\beta_{13} * X_{j 3}+\cdots+\varepsilon_{j} \\
U_{j}=V_{j}+\varepsilon_{j}
\end{gathered}
$$

where,

$V_{j}$ : Deterministic portion of residential utility,

$\beta_{1}, \beta_{2}, \cdots, \beta_{3}$ : Coefficients of explanatory variables,

$X_{j 1}, X_{j 2}, X_{j 3}$ : Independent variables,

$\varepsilon_{j}$ : Stochastic portion of the utility function.

$$
\operatorname{Pr}(i: C)=\frac{V_{i}}{\sum_{C} V_{j}}
$$

where,

$\operatorname{Pr}(i: C):$ is the probability of the decision-maker choosing alternative $i$ from set $\mathrm{C}$

$V_{j}$ : is the systematic component of the utility of alternative $j$.

\section{Results and Discussion}

As mentioned in previous sections, Afghanistan has one of the youngest populations in the world. Our survey also showed that more than half of the participants are aged below 30 years. Particularly, female respondents are very young as $59 \%$ are teenagers. Figure 1 shows the age differences between men and women. Generally, Afghans get married quite at young age. However, the current generation, particularly, girls do not want to get married at younger ages (Figure 2). Marriage can play an important role in purposes and patterns of trips; therefore, it might be important to consider these factors while planning public transport.

With reference to the findings of our survey, it can be stated that most of the residents of Kandahar City have a fair amount of family income ranging from 20,000 to 40,000 per month; which is a good amount in the context of Afghanis$\tan$. This is one of the main reasons for high ownership rate of private vehicles particularly cars and motorcycles. Though, the female members of almost all families in Kandahar City do not own any types of vehicles and the vehicles are owned by men. The results show that $38.5 \%$ of male residents own at least one motorcycle, $21.0 \%$ have private cars followed by bicycle with a percentage of $14 \%$. Furthermore, only $26.2 \%$ of men and/or boys were recorded without possession of private vehicles. However, as shown in Figure 3; almost all (98.2\%) of female residents of Kandahar City do not own any types of private vehicles.

A very small and negligible number of girls are registered to own bicycles and motorcycles. These numbers are associated with the cultural and religion constraints and are not really linked to the economic conditions of families. With 


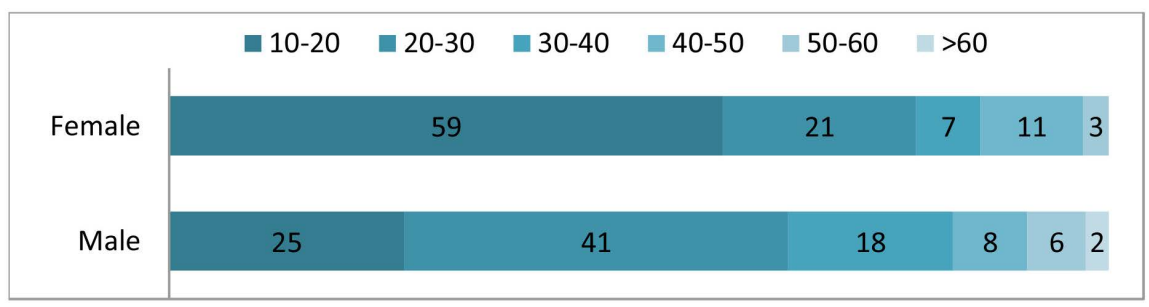

Figure 1. Age variations of male and female respondents (Years).

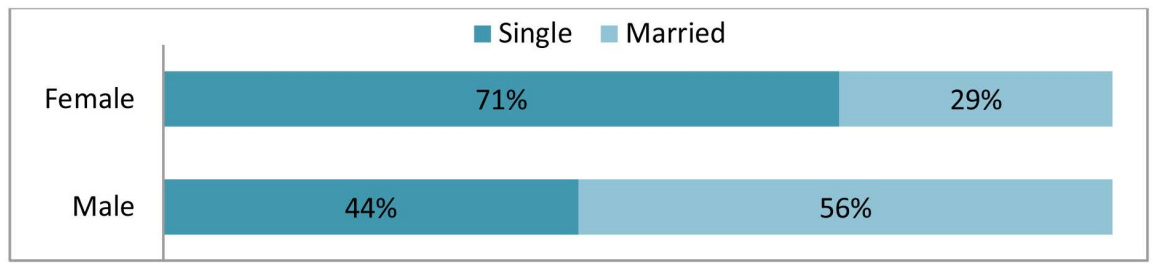

Figure 2. Marital status of male and female respondents.

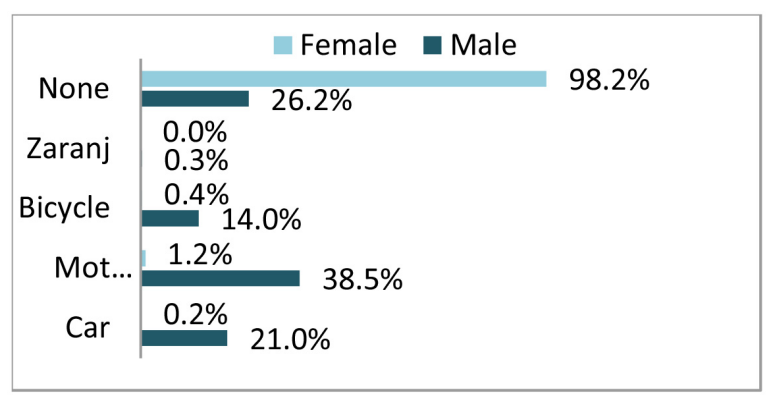

Figure 3. Private vehicle ownership for male and female respondents.

respect to some contextual issues, female do not want to drive or ride, so there is no meaning of owning any cars, motorcycles and bicycles.

Multiple researchers have found that type of employment and occupations are directly linked to the trip patterns and use of public transportation [6] [7] [8]. Normally, the working women will travel in peak hours while nonworking female will travel during off-peak hours. The female of Kandahar city are mostly unemployed and like to stay at homes and take care of their families. Figure 4 shows the occupational statistics of women living in Kandahar city. $73.6 \%$ of women in Kandahar city are not working outside their homes and $21.1 \%$ are students and taking trips to educational centers alone. A very small portion of only $3.2 \%$ is governmental employees. However, this is not the case for male respondents as most of them are employed in governmental offices and/or private organizations. According to the results only $12.7 \%$ men are unemployed which also include those who are retired.

Education levels of the participants are also considerably different for women and men. As revealed by Figure 5, just $4.0 \%$ of female residents of Kandahar city were able to pursue higher education. However, for male respondents the case is much better as $32.2 \%$ have obtained a bachelor or higher degree. The most 


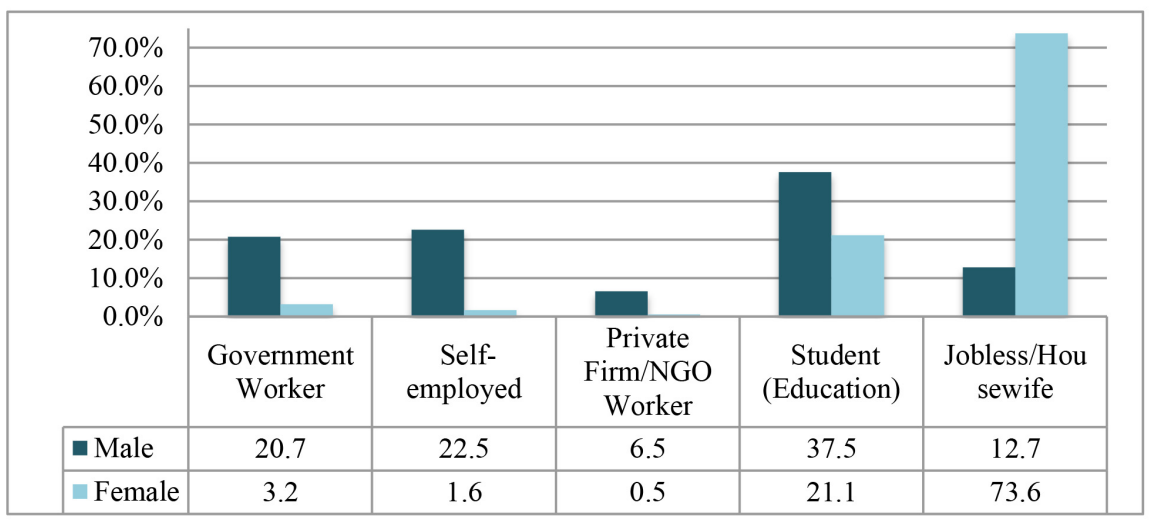

Figure 4. Occupational disparities with respect to gender.

\begin{tabular}{|c|c|c|}
\hline \multicolumn{3}{|c|}{ Male Female } \\
\hline Illiterate & 10.8 & 46.9 \\
\hline Literate (Read \& Write) & $5.6 \quad 13.2$ & \\
\hline Primary School & 10.5 & \\
\hline Secondary School & 15.6 & \\
\hline High Schol & 26.5 & 13.5 \\
\hline Bachelor or Higher & 32. & 4.0 \\
\hline
\end{tabular}

Figure 5. Percentage of education levels.

disappointing point is that almost half (46.9\%) of women in Kandahar city are illiterate.

These huge occupational and educational differences should be considered in design, planning and operation of all public modes. As mentioned earlier, the trip patterns, travel times, number of daily trips, major trip destinations and other trip related attributes are always lined to education and the type and availability of occupations and jobs. Likewise, the gender differences are also bond to the trip attributes, particularly in Kandahar city and we believe these disparities are huge and will strongly affect the services of public modes for both men and women.

\section{1) Disparities of trip patterns}

As discussed in previous sections, the trip patterns of male and female are almost always different. Generally, these differences are linked to gender inequality, education, socialization, culture and urban structures [2] [23] [24]. Others have associated these gaps with the split role of men and women in households and the labor market [3]. It is also found that the trip patterns will change with financial conditions of families. It is believed that in order to save money, poor women will most likely choose walking rather than using public transportation [4].

Like residents of other cities in the developing world, women of Kandahar city also have different trip dairies with comparison to their men counterparts. The 
findings of this study revealed that besides home based trips, majority of women travel for education and work purposes (Figure 6). Additionally, $26.8 \%$ of female trips were made for going to educational centers and $13.9 \%$ for going to works. These numbers are followed by $4.6 \%$ of shopping trips. There are very few trips made for recreational activities (1\%). However, male respondents have more dispersed patterns. Likewise, $20.7 \%$ of the trips made by male residents of Kandahar city are for going to work. This is followed by educational trips as $18 \%$ of trips are made for reaching schools and universities. Compared to women, there are some manmade trips for recreational and business purposes with numbers of $3.1 \%$ and $2.0 \%$ respectively.

Modes used for making the above trips are also very different for men and women in Kandahar city. As mentioned earlier, there are some limitations and restrictions for women during their trips. One of the major issues is the disability of women to drive a car or ride a motorcycle/bicycle. With respect to multiple cultural and religious regulations; women do not want to be seen driving in public. Therefore, the option of using private cars and/or other two-wheelers does not exist for women. They have to walk, take a ride with other male members of the family or hire a taxi cab. These claims are confirmed in Figure 7 which shows that the majority of female trips are made by walking i.e. $33.5 \%$ which is almost double of the walking trips by male residents (16.8\%). Similarly, the use of currently available public modes is also higher for women in comparison to men. Only $3.1 \%$ of men were reported to use public modes of taxi and zaranj taxi in their daily trips, while $16.5 \%$ of women used these public modes on daily basis which is mainly due to lack of other transport modes.

Clear differences were noticed in number of daily trips and distance travelled among men and women. Findings of many studies claim that women are likely to make more trips over short distances [7] [25]. However, this fact does not complement our findings in terms of number of the trips made by women; yet, the claim of shorter trips coincides with the case of Kandahar city. Our results presented in Table 2 show that men are traveling an average of 3.3 trips per day while women are reported to make 2.7 daily trips. Two trips mean going to work or school and coming back to home; so 2.7 trips per day show that women are not making many trips. Again the reason behind this fact is linked to the culture as women do not go outside of their houses unless there is an urgent work.

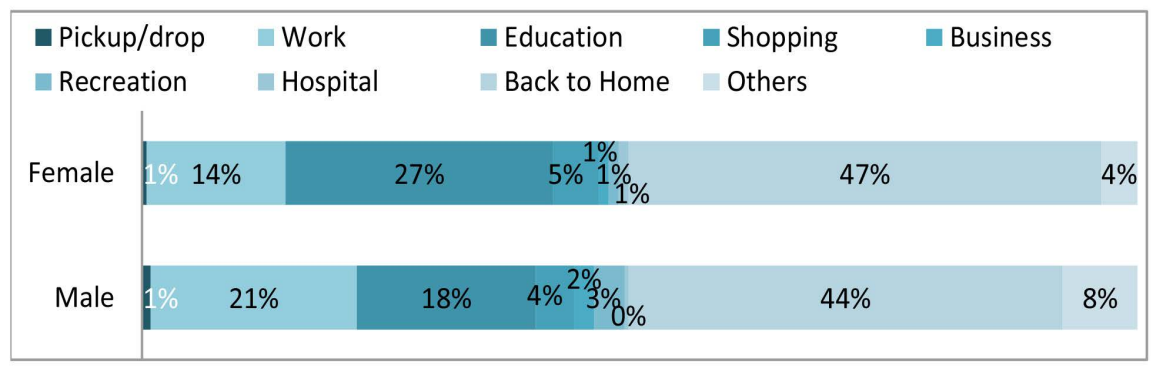

Figure 6. Comparison of trip purposes for male and female participants. 


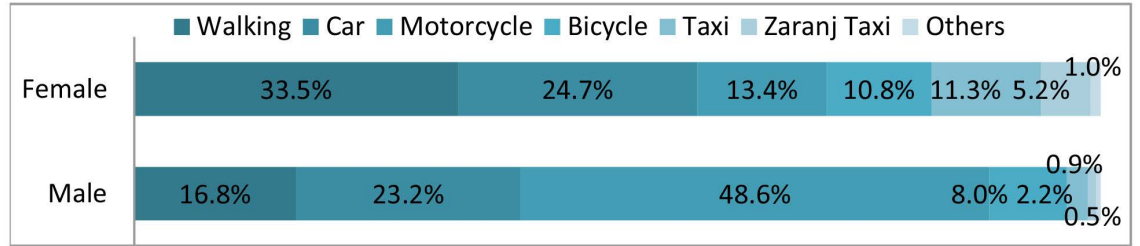

Figure 7. Descriptive statistics of travel modes for men and women.

Table 2. Results of simple ANOVA-Test for trips.

\begin{tabular}{cccccccc}
\hline Groups & Count & $\begin{array}{c}\text { Number } \\
\text { of Trips }\end{array}$ & $\begin{array}{c}\text { Trips/day } \\
\text { /person }\end{array}$ & $\begin{array}{c}\text { Sum } \\
(\mathbf{k m})\end{array}$ & $\begin{array}{c}\text { Average } \\
(\mathrm{Km})\end{array}$ & Variance & P-Value \\
\hline Male Respondents & 530 & 1253 & 3.3 & 8617 & 16.23 & 696.49 & 0.041 \\
Female Respondents & 73 & 194 & 2.7 & 718.9 & 9.85 & 106.54 & \\
\hline
\end{tabular}

When the number of the trips increases, the distance travelled might also increase, so it is understandable that on average, women travel over shorter lengths compared to men. The results show that every man in Kandahar city travels about $16.2 \mathrm{~km}$ per day which is much higher compared to the length of $9.8 \mathrm{~km}$ travelled by women. With similar manner, the length of every trip is also shorter for female residents. Every trip made by men will cover an average length of $5.1 \mathrm{~km}$, while for women the average length of each trip is just $3.7 \mathrm{~km}$.

These differentiating attributes of daily trips for men and women are very vital for planning and operating public transit. Women of Kandahar city are not making multiple trips on daily basis and most of their trips are for education purposes. This will mean that all major and minor roads leading to main and populated educational centers of the city should be added to the network of public transportation system.

As shown in Figure 8, female respondents show immense eagerness in using public transit i.e. bus, if available in the future. However, for men; motorcycle and private car remains to be the preferred modes even after introduction of regular bus system. As mentioned earlier, women do not ride motorcycles, however, some girls particularly students travel by motorcycles (as passengers) with male members of their families. Almost every household of Kandahar city has at least one motorcycle; thus availability and company of a male family member which provides extra safety is the main reason for showing interest in using motorcycle in future as well. Still, their first choice will be regular bus system.

\section{2) Other Results}

In order to obtain a comparative insight of the data in terms of gender relevant attributes, the data was divided into two parts and every set was analyzed separately. The first set included the data obtained from the responses of male participants while the second set was designated for the female respondents. However, all the variables considered for the model such as income, car and motorcycle ownership etc. were kept unchanged for both sets and the data was analyzed through Multinomial Logit Model approaches. 


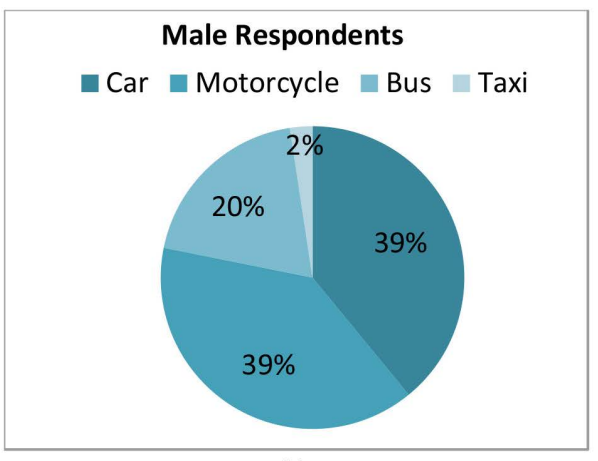

(a)

Female Respondents

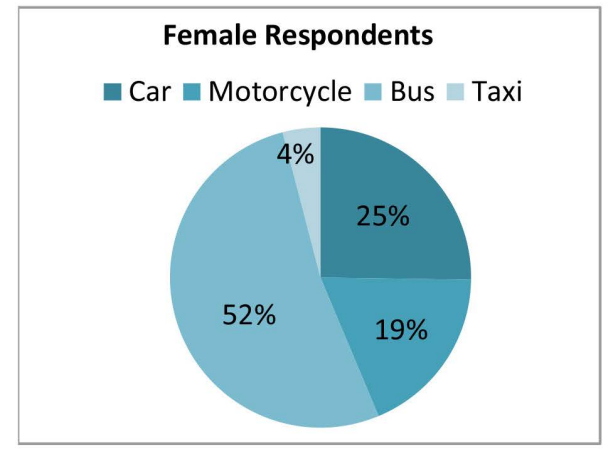

(b)

Figure 8. SP choices for male \& female respondents.

The results shown in Table 3, revealed a clear difference in responses of men and women. Almost all of the selected variables are statistically significant for male respondents, however, the results obtained from the female respondents show limited significance. Marital status, car ownership, motorcycle ownership, income level and trip attributes will strongly affect the mode choice of male residents in Kandahar city. The results further show that the respondents are more sensitive to travel time compared to the costs of the four modes selected for the study. This means they like to get to their destinations faster even if it costs a little more. Still, at -1.826 the variable of travel cost is also significant and will have an impact. Therefore, the allocation of travel fare, selection of proper stops/ stations, speed and headway of public transit will be contributing factors for attracting ridership.

On the other hand, $\mathrm{t}$-values for women related data show that women will also consider the time and cost of the trips while choosing travel modes. Though most of women in Kandahar city are not working, still income will affect their mode choice behavior. In the context of Kandahar city this makes a perfect sense. Almost all of women are financially dependent on men and the transportation fares are also provided by male members of the families. The insignificance of vehicle ownership proves that inability to drive, ride or cycle will not affect their mode choice decisions. So all they have is the available public modes and will have to use those modes under all circumstances. As a result of all these factors along with cultural and contextual issues, it is understandable that public 
Table 3. Results of Multinomial Logit Model for male and female.

\begin{tabular}{|c|c|c|c|c|}
\hline \multirow{2}{*}{ Variables } & \multicolumn{2}{|c|}{ MNL for Male Respondents } & \multicolumn{2}{|c|}{ MNL for Female Respondents } \\
\hline & Coefficient & $\mathrm{t}$-statistics & Coefficient & t-statistics \\
\hline Taxi Constant & 3.221 & 12.161 & 2.736 & 3.894 \\
\hline Motorcycle Constant & 2.730 & 16.026 & 1.508 & 3.961 \\
\hline Bus Constant & 2.446 & 10.978 & 2.824 & 5.645 \\
\hline Marital Status & -0.410 & -3.421 & -0.714 & -1.686 \\
\hline Car Ownership & 0.994 & 6.019 & 0.361 & 0.275 \\
\hline Motorcycle Ownership & 0.206 & 1.467 & 0.585 & 0.505 \\
\hline Incomel $(0-10,000)$ & -0.829 & -3.604 & -0.594 & -1.862 \\
\hline Income2 $(10,000-30,000)$ & -0.495 & -3.460 & -0.764 & -1.502 \\
\hline Income3 $(30,000-50,000)$ & -0.153 & -1.024 & -0.806 & -1.403 \\
\hline Travel Cost & -0.002 & -1.826 & -0.003 & -1.581 \\
\hline Travel Time & -0.010 & -3.063 & -0.007 & -1.888 \\
\hline Rho-Square & \multicolumn{2}{|c|}{0.209} & \multicolumn{2}{|c|}{0.204} \\
\hline Adjusted Rho-Square & \multicolumn{2}{|c|}{0.203} & \multicolumn{2}{|c|}{0.169} \\
\hline
\end{tabular}

modes will be used by female residents of Kandahar city irrespective of the quality of their services and other attributes. It is noteworthy to state that these results were led from the condition of free available modal choices in our SP survey.

\section{Conclusions}

This study is an attempt to evaluate the need of gender relevant issues for planning public transit for Kandahar city of Afghanistan. Our findings show distinct and clear disparities in socio-demographic characteristics of men and women of Kandahar city. Almost all of women do not own any types of personal vehicles, they are less educated and do not have jobs. All these issues will play an important role in mode choice selection as well as their trip arrangements and generations.

Likewise, there is a huge gap between trip characteristics and patterns of men and women. Majority of female trips are for educational purposes while male trips are more dispersed over multiple activities. Motorcycle is the most dominant and preferred mode for men, while women are mostly walking or using available public transit. Compared to men, women were recorded to have lesser trips per day over short distances. Transportation choices of women are also limited to walking, accompanying other male members of family or using public modes. However, men have the luxury of using their private cars, motorcycles and bicycles together with all those options available for women.

Considering all these issues, if a system is designed with reference to the travel patterns of men alone, there is no way the system will offer proper services to 
women. Special consideration of all women-oriented trips attributes and patterns should be properly considered and included in every step of planning, designing and operating public transit sector. The scheduling, stop allocation, and route selection are the most essential considerations for provision of public transport that could serve both men and women.

As mentioned in earlier sections, the government has very limited control over the current paratransit system which has immensely affected the quality and efficiency of the system. Lack of proper management, limited coverage, poor route network, fluctuated fares, very old vehicles, unprofessional competition among the suppliers and some other issues are the main causes of the inefficient paratransit system in Kandahar city. The relevant governmental and private organizations should pay attention to the level of service of the available public transit in Kandahar city which we believe will directly affect and increase the female ridership.

In order to overcome the great challenges, barriers and obstacles posed by people, culture and traditions, security and conservative society; it will be essential for the government to work in partnership with all stakeholders from various sectors, administrations and civil societies and mainstream the learnings and policies in more sustainable and consistent ways. Including women in decision making and policy developing procedures will enrich the decisions to address the transportation needs of women. Eliminating physical and safety barriers are also vital for female travelers. Building proper and women-friendly stops, allowing women to get on and off close to their origins and destinations and an easy way of fare collection could be some of the measures for limiting these barriers in Kandahar city. Provision of a system with some "Women Only" vehicles will be the easiest and perfect solution to limit most of the cultural and religious barriers. These vehicles will enable women to set/stand close to each other with a safer feeling. Hiring female conductors will not only provide convenient services to the users, but will also create job opportunities for some women. Moreover, these vehicles will also arrange their trip schedules and routes with reference to the needs of women which could offer better services compared to the normal vehicles.

It is very obvious that a lot of budget is required for implementing the above policies on provincial or country level. Yet with respect to the fact that women comprise almost half of population in Afghanistan, it is very important for the government to allocate special budget and initiate proper and distinct programs for tackling the gender inequalities in the transport sector. Subsidization of the public transit is a very common phenomenon in most of the countries at initial stages and is considered to be an effective way of providing convenient and good-for-all transportation system.

\section{Conflicts of Interest}

The authors declare no conflicts of interest regarding the publication of this paper. 


\section{References}

[1] Riverson, J., Kunieda, M., Roberts, P., et al. (2005) An Overview of Women's Transport Issues in Developing Countries. Transportation Research Board, Annual Meeting CD-ROM.

[2] Romer, H.R., Poulsen, H., Oldrup, H.H., et al. (2007) Gender Mainstreaming European Transport Research and Policies, Building the Knowledge Base and Mapping Good Practices. (TRANSGEN), University of Copenhagen.

[3] Hasson, Y. and Polevoy, M. (2011) Gender Equality Initiatives in Transportation Policy: A Review of the Literature. Women's Budget Forum.

[4] Turner, J. (2012) Urban Mass Transit, Gender Planning Protocols and Social Sustainability: The Case of Jakarta. Research in Transportation Economics, 34, 48-53. https://doi.org/10.1016/j.retrec.2011.12.003

[5] Sarmiento, S. (1998) Household, Gender and Travel in Women's Travel Issues. Proceedings from the Second Nation Conference, Office of Highway Information Management, 97-024.

[6] Claudia, N. and Lenz, B. (2005) Gender Differences in Travel Patterns: Role of Employment Status and Household Structure. Research on Women's Issues in Transportation, Report of a Conference, 2, 114-123.

[7] Peters, D. (2002) Gender and Transport in Less Developed Countries: A Background Paper for the Expert Workshop. Gender Perspectives for Earth Summit 2002: Energy, Transport Information for Decision-Making, Federal Ministry for the Environment, Nature Protection and Nuclear Safety; Heinrich Boell Foundation, Berlin.

[8] Kudat, A. and Cernea, M. (1996) Strengthening Ashgabat's Urban Transport System, "Social Assessments for Better Development: Case Studies in Russia and Central Asia". The World Bank, Washington DC, 165-187.

[9] Buehler, R. and Pucher, J. (2010) Demand for Public Transport in Germany and the USA: An Analysis of Rider Characteristics. Transport Reviews, 32, 541-567. https://doi.org/10.1080/01441647.2012.707695

[10] Duchene, C. (2011) Gender and Transport, Discussion Paper. The International Transport Forum on Transport for Society, Leipzig, 11.

[11] Lambrick, M., Rainero, L., Andrew, C., et al. (2010) Recognise the Barriers to Women's Safe, Efficient and Affordable Travel. UN-Women. http://www.endvawnow.org/en/articles/286-recognise-the-barriers-to-womens-safe -efficient-andafordable-travel.html

[12] Sham, R., Omar, N. and Amat, D.W. (2013) Women and Crime in Central Business District. Asian Behavioral Studies, 3, 1-12.

[13] Sarkar, M.S. and Partheeban, P. (2011) Abandon All Hope, Ye Who Enter Here, Women's Issues in Transportation. Transport Research Board, 2, 74-84.

[14] Needle, J.R. and Cobb, M. (1997) Improving Transit Security: Synthesis of Transit Practice 21. Transit Cooperative Research Program. National Academy Press, Washington DC.

[15] Sideris, A.L. and Fink, C. (2008) Addressing Women's Fear of Victimization in Transportation Settings, a Survey of U.S. Transit Agencies. Urban Affairs Review, 44, 554-587. https://doi.org/10.1177/1078087408322874

[16] Henderson, S. and Associates, R.H. (2015) Women and Transport: Moving Forward. The Scottish Executive Central Research Unit.

[17] Bhatt, A., Menon, R. and Khan, A. (2015) Women's Safety in Public Transport: A 
Pilot Initiative in Bhopal. The WRI Ross Center for Sustainable Cities, Bhopal.

[18] Zelinka, A. and Brennan, D. (2001) SafeScape: Creating Safer, More Livable Communities through Planning and Design. American Planning Association Planner's Press, Washington DC.

[19] Babinard, J. (2011) World Bank Gender Transport Surveys: An Overview. Transport Notes Series, No. TRN 43. World Bank, Washington DC.

[20] Golden, S. (2008) Gender Mainstreaming in Transport for London. Transport for London.

[21] Dahlström, K. (2007) National Travel Survey RES 2005-2006. Swedish Institute for Transport and Communications Analysis (SIKA).

[22] CSO-Afghanistan (2017) Statistical Year Book of Afghanistan 2016-17. Central Statistic Organization, Kabul.

[23] Biljana, R.P. and Jovi, J. (2014) Women and Transportation Demands in Rural Serbia. Rural Studies, 36, 207-218. https://doi.org/10.1016/j.jrurstud.2014.08.002

[24] Dobbs, L. (2005) Wedded to the Car: Women, Employment and the Importance of Private Transport. Transport Policy, 12, 266-278.

https://doi.org/10.1016/j.tranpol.2005.02.004

[25] Macdonal, H.I. (1999) Women's Employment and Commuting: Explaining the links. Planning Literature, 13, 267-283.

https://doi.org/10.1177/08854129922092397 